\title{
Induction of Manganese Superoxide Dismutase in Rat Cardiac Myocytes Increases Tolerance to Hypoxia 24 Hours after Preconditioning
}

\author{
Nobushige Yamashita, ${ }^{\star \ddagger}$ Masashi Nishida, ${ }^{\star \ddagger}$ Shiro Hoshida, ${ }^{\star}$ Tsunehiko Kuzuya, ${ }^{\star \ddagger}$ Masatsugu Hori, ${ }^{\star}$ Naoyuki Taniguchi, ${ }^{\$}$ \\ Takenobu Kamada, ${ }^{*}$ and Michihiko Tada** \\ * The First Department of Medicine, ${ }^{\ddagger}$ The Department of Pathophysiology, and ${ }^{\S}$ The Department of Biochemistry, Osaka University \\ Medical School, Suita, Osaka, Japan 565
}

\begin{abstract}
Manganese superoxide dismutase (Mn-SOD) is induced in ischemic hearts $24 \mathrm{~h}$ after ischemic preconditioning, when tolerance to ischemia is acquired. We examined the relationship between Mn-SOD induction and the protective effect of preconditioning using cultured rat cardiac myocytes. Exposure of cardiac myocytes to brief hypoxia $(1 \mathrm{~h})$ decreased creatine kinase release induced by sustained hypoxia $(3 \mathrm{~h})$ that follows when the sustained hypoxia was applied $24 \mathrm{~h}$ after hypoxic preconditioning (57\% of that in cells without preconditioning). The activity and content of Mn-SOD in cardiac myocytes were increased $24 \mathrm{~h}$ after hypoxic preconditioning (activity, 170\%; content, 139\% compared with cells without preconditioning) coincidentally with the acquisition of tolerance to hypoxia. Mn-SOD mRNA was also increased 20-40 min after preconditioning. Antisense oligodeoxyribonucleotides corresponding to the initiation site of Mn-SOD translation inhibited the increases in the Mn-SOD content and activity and abolished the expected decrease in creatine kinase release induced by sustained hypoxia after 24 h of hypoxic preconditioning. Sense oligodeoxyribonucleotides did not abolish either Mn-SOD induction or tolerance to hypoxia. These results suggest that the induction of Mn-SOD in myocytes by preconditioning plays a pivotal role in the acquisition of tolerance to ischemia at a later phase $(24 \mathrm{~h}$ ) of ischemic preconditioning. (J. Clin. Invest. 1994. 94:2193-2199.) Key words: cardiac myocytes • hypoxia-reoxygenation • manganese superoxide dismutase $\bullet$ preconditioning • antisense oligodeoxyribonucleotides
\end{abstract}

\section{Introduction}

Prolonged ischemia causes irreversible cell death and results in myocardial infarction in heart tissue. However, recent findings suggest that sublethal brief ischemia exhibits a protective effect against prolonged lethal ischemia that follows in the heart. The induction of tolerance to ischemia by preceding brief ischemia ("preconditioning phenomenon") was reported in in vivo models $(1,2)$ and also in clinical reports $(3-5)$. In most reports,

Address correspondence to Masashi Nishida, The First Department of Medicine, The Department of Pathophysiology, Osaka University Medical School, 2-2 Yamadaoka, Suita, Osaka, Japan 565.

Received for publication 4 March 1994 and in revised form 5 August 1994.

J. Clin. Invest.

(c) The American Society for Clinical Investigation, Inc.

0021-9738/94/12/2193/07 \$2.00

Volume 94, December 1994, 2193-2199 preconditioning phenomenon was observed soon after brief sublethal ischemia and did not extend over $3 \mathrm{~h}$ after the ischemia $(6,7)$.

Recently, we found that the preconditioning phenomenon, which appeared soon after sublethal ischemia and disappeared $3 \mathrm{~h}$ after the ischemia, reappeared $24 \mathrm{~h}$ after the initial ischemia in a canine occlusion-reperfusion model of myocardial infarction (6). Marber et al. (8) also found that the protective effect of sublethal ischemia was observed $24 \mathrm{~h}$ after the ischemia in a rabbit model. The mechanism of the late phase effect of preconditioning is not clear. Although preconditioning phenomenon found at soon after ischemia was not related to de novo synthesis of proteins (9), the late phase effect of sublethal ischemia observed $24 \mathrm{~h}$ after ischemia highly correlated to the induction of proteins, mitochondrial manganese superoxide dismutase (Mn-SOD) (10), or heat shock proteins (HSPs) ${ }^{1}(8)$. Heat stress, which induces various proteins including radical scavengers (Mn-SOD, catalase) and HSPs, also increased the resistance of hearts to myocardial ischemia at the same time course as protein induction after $24 \mathrm{~h}$ of whole-body hyperthermia $(8,11,12)$. However, the direct proof that the induction of these proteins is responsible for the acquisition of the tolerance to ischemia has not been examined yet.

In this study, we attempted to demonstrate a direct association between Mn-SOD induction in myocytes and the acquisition of tolerance to ischemia at a late phase of preconditioning using cultured cardiac myocytes exposed to simulated ischemia.

\section{Methods}

Cell culture. Cardiac myocytes were isolated and cultured from neonatal rat hearts based on the method reported previously (13). Briefly, neonatal Wistar-Kyoto rats (six litters) were anesthetized with ether and then their hearts were quickly removed and immersed in PBS $(\mathrm{NaCl}, 8.0 \mathrm{~g} /$ liter; $\mathrm{Na}_{2} \mathrm{HPO}_{4}, 1.5 \mathrm{~g} /$ liter; $\mathrm{KH}_{2} \mathrm{PO}_{4}, 0.29 \mathrm{~g} /$ liter; $\mathrm{K}_{2} \mathrm{HPO}_{4}, 0.2 \mathrm{~g} /$ liter) containing calcium $(0.1 \mathrm{~g} /$ liter $)$ adjusted to $\mathrm{pH}$ 7.4. After blood had been carefully washed out, the excised ventricles were cut into 1 2-mm cubes, placed in $15 \mathrm{ml}$ of PBS containing $0.1 \%$ collagenase, and then agitated using a magnetic stir bar at slow speed (100-150 rpm) for $10 \mathrm{~min}$ at $37^{\circ} \mathrm{C}$. The dissociated cells were collected by decantation. After discarding the cells from the first treatment, cells from the succeeding three enzymatic treatments were pooled, centrifuged for 5 min at $120 \mathrm{~g}$, and then resuspended in $30 \mathrm{ml}$ of Dulbecco's modified Eagle's medium (DME) with a high glucose concentration $(4,500 \mathrm{mg} /$ liter $)$ supplemented with penicillin $\mathrm{G}(400 \mathrm{U} / \mathrm{ml})$, streptomycin $(200 \mu \mathrm{g} /$ $\mathrm{ml}$ ), and $10 \%$ FBS. To obtain myocytes selectively, dissociated cells were preplated for $1 \mathrm{~h}$ and then unattached myocytes were collected. Myocytes were plated on culture dishes at a density of $3.1 \times 10^{4} / \mathrm{cm}^{2}$.

1. Abbreviations used in this paper: CK, creatine kinase; HSP, heat shock proteins; NBT, nitroblue tetrazolium; ODN, oligodeoxyribonucleotides. 
After $3 \mathrm{~d}$ in culture, the percentage of beating myocytes exceeded $90 \%$ in each preparation.

Experimental protocol. Isolated cells were cultured in DME with $10 \%$ FBS and 5-bromo- $2^{\prime}$-deoxyuridine $(100 \mathrm{mM})$ for $48 \mathrm{~h}$ at $37^{\circ} \mathrm{C}$ perfused with a normoxic gas mixture $\left(95 \%\right.$ room air, $5 \% \mathrm{CO}_{2} ; \mathrm{pO}_{2}$ $143 \mathrm{mmHg}$ ), and then the medium was switched to serum-free DME with high concentrations of glucose, insulin $(10 \mathrm{mg} / \mathrm{ml})$, and transferrin $(10 \mathrm{mg} / \mathrm{ml})$. After $18-24 \mathrm{~h}$ in serum-free medium, the cells were exposed to various gas conditions. In experiments assessing Mn-SOD induction by hypoxic preconditioning, cultured myocytes were exposed to a hypoxic gas mixture (first hypoxia) $\left(94 \% \mathrm{~N}_{2}, 5 \% \mathrm{CO}_{2}\right.$, and $1 \%$ $\mathrm{O}_{2} ; \mathrm{pO}_{2} 7 \mathrm{mmHg}$ ) for $1 \mathrm{~h}$ in DME with a low glucose concentration $(1,000 \mathrm{mg} /$ liter $)$. Then the perfusion gas was switched to the normoxic gas mixture (first reoxygenation), followed by culturing in DME with a high glucose concentration up to $36 \mathrm{~h}$ after reoxygenation. In the control group, cells were exposed to a normoxic gas mixture instead of a hypoxic gas mixture for the first hour. In experiments assessing myocyte injury, cells were exposed to a hypoxic gas mixture (second hypoxia) in DME without glucose for $3 \mathrm{~h}$ at $0,3,12,24$, and $36 \mathrm{~h}$ after the first reoxygenation and then were reoxygenated for $1 \mathrm{~h}$ (second reoxygenation) with a normoxic gas mixture in the same medium. In the control group, cultured cells were exposed to a normoxic gas mixture instead of the first hypoxia.

In experiments involving antisense oligodeoxyribonucleotides (ODN), antisense and sense ODN (22 mer) involving the initiation site of rat Mn-SOD transcription were synthesized and applied to the preconditioned group $(a)$ for $18 \mathrm{~h}$ before the first hypoxia, $(b)$ from 18 $\mathrm{h}$ before the first hypoxia to $24 \mathrm{~h}$ after reoxygenation, or $(c)$ for $24 \mathrm{~h}$ after reoxygenation at $1.5 \mu \mathrm{M}(13)$. As all three protocols gave the same results (data not shown), the second protocol was used for the rest of the experiments. In experiments involving staurosporine ( 100 $\mathrm{nM}$ ), it was added to preconditioned cells for $24 \mathrm{~h}$ after the first hypoxia.

We performed more than five batches of culture for each set of experiments. There was no significant difference between batches. We compared two statistical calculations; the number of culture batches as $n$ value for statistical analysis and the number of all accumulated data (batches $\times$ dishes) as $n$ value to compensate for inter-dish deviation and inter-culture batch deviation. As both methods gave the same statistical results, we used the former method to compare multiple groups.

Measurement of Mn-SOD activity: SOD activity in cultured myocytes with or without hypoxic preconditioning was determined by the nitroblue tetrazolium (NBT) method (14). Briefly, myocytes were scraped into $1 \mathrm{ml}$ of cold PBS, sonicated on ice, and then centrifuged at $800 \mathrm{rpm}$ for $5 \mathrm{~min}$. The supernatant was added to the reaction mixture of NBT with xanthine-xanthine oxidase, and then the SOD activity in the supernatant was measured colorimetrically as inhibitory activity toward blue formazan formation by SOD in the reaction mixture. To determine Mn-SOD activity, the assay was repeated in the presence of potassium cyanide ( $1 \mathrm{nM}$ ) to inhibit copper, zinc-superoxide dismutase $(\mathrm{Cu}, \mathrm{Zn}$-SOD) activity. $\mathrm{Cu}, \mathrm{Zn}-\mathrm{SOD}$ activity was determined by subtraction of the Mn-SOD activity from the total SOD activity.

Measurement of Mn-SOD content. The Mn-SOD content in the supernatant of a cell homogenate was determined by means of an enzymelinked immunosorbent assay (ELISA)(15). After an anti-rat Mn-SOD polyclonal antibody had been attached to immunoplates overnight at $4^{\circ} \mathrm{C}$ and the plates had been blocked with $0.5 \%$ (wt/vol) ovalbumin, the supernatant of a cell homogenate (prepared as above) was added to the wells, followed by incubation at $37^{\circ} \mathrm{C}$ for $1 \mathrm{~h}$. The wells were washed three times with the washing buffer (PBS with $0.05 \%$ Tween), and then anti-rat Mn-SOD polyclonal antibody conjugated with horseradish peroxidase was added to each well. After $1 \mathrm{~h}$ at $37^{\circ} \mathrm{C}$, the wells were washed four times with the washing buffer, and then the horseradish peroxidase reaction was measured with a microplate reader (Corona Electric, Katsuta, Japan). The Mn-SOD activity and content were corrected for the protein concentration in the supernatant determined using a protein assay kit (Bio-Rad Laboratories, Richmond, CA).

Northern analysis of Mn-SOD $m R N A$. Total RNA was isolated from cultured cells using the guanidinium thiocyanate extraction method

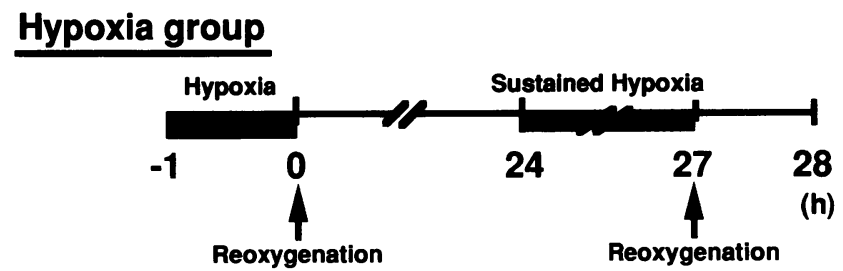

Control group

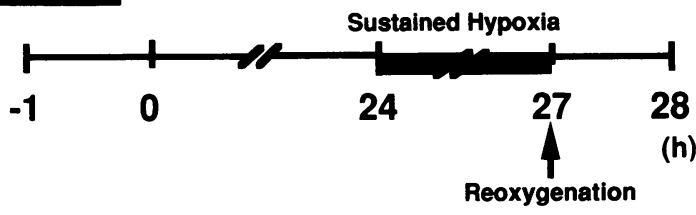

Figure 1. Experimental protocol. Cultured myocytes were exposed to first hypoxia for $1 \mathrm{~h}$ (preconditioning) followed by normoxic first reoxygenation. After $24 \mathrm{~h}$ of first reoxygenation, the cells were exposed to second sustained hypoxia for $3 \mathrm{~h}$, followed by $1 \mathrm{~h}$ of reoxygenation (second reoxygenation).

(16). $10 \mu \mathrm{g}$ of total RNA was size-fractionated by gel electrophoresis, blotted onto a nylon membrane, and then hybridized for $24 \mathrm{~h}$ with cDNA probes labeled by the random primer method. The membranes were washed with $2 \times \mathrm{SSC}$ containing $0.1 \%$ SDS at $55^{\circ} \mathrm{C}$ and then exposed to Kodak X-Omat-RR film for $24 \mathrm{~h}$ for Mn-SOD and for $6 \mathrm{~h}$ for $\beta$-actin. The autoradiogram was analyzed by a computerized gel scanner (Imaging Research Inc., St. Catherines, Ontario, Canada), and $\mathrm{Mn}$-SOD signals were normalized to $\beta$-actin signals to cancel the variation of loading. The cDNA probe used for Mn-SOD hybridization was a Stul/SacIl fragment ( $465 \mathrm{bp}$ ) of a rat Mn-SOD cDNA (17). The cDNA for $\beta$-actin was a PstI/HindIII fragment containing a 500-bp portion of the coding region of the human $\beta$-actin gene.

Measurement of creatine kinase $(C K)$. CK activity in the culture medium was measured $1 \mathrm{~h}$ after reoxygenation from sustained hypoxia by the German Society for Clinical Chemistry method (18). Briefly, after mixing of the culture medium with assay solution, the assay reaction was started by the addition of creatine phosphate. The production of NAD $(P) H$ was measured at $340 \mathrm{~nm}$.

Materials. The cell culture apparatus was purchased from Becton Dickinson (Mountain View, CA). The chemicals and reagents for cell culture were purchased from Gibco Laboratories (Gaithersburg, MD), Sigma Immunochemicals (St. Louis, MO), and Wako (Osaka, Japan).

\section{Results}

Cellular models of hypoxic preconditioning. We examined whether the preconditioning phenomenon could be mimicked in cultured myocytes by exposing them to brief hypoxia followed by reoxygenation before exposure to sustained hypoxia (Fig. 1). Spontaneous beating of cultured myocytes, which ceased or decreased under the first brief hypoxic condition, restarted or was restored without hypercontraction or bleb formation on the first reoxygenation. The control cells were treated in the same way as the preconditioned myocytes except that the cells were exposed to the normoxic condition for the first hour. $\mathrm{CK}$ activity in culture medium after $1 \mathrm{~h}$ of hypoxia $(0.15 \pm 0.01$ $\mathrm{U} /$ liter) was the same as the CK activity in culture media from control cells $(0.16 \pm 0.02 \mathrm{U} /$ liter $)$ or the value of culture medium alone $(0.12 \pm 0.02 \mathrm{U} /$ liter $)$, which suggests that myocytes were not injured by the first hypoxia. On the second reoxygenation after the second sustained hypoxia after $24 \mathrm{~h}$ of the first reoxygenation, the cells without preconditioning restarted spontane- 


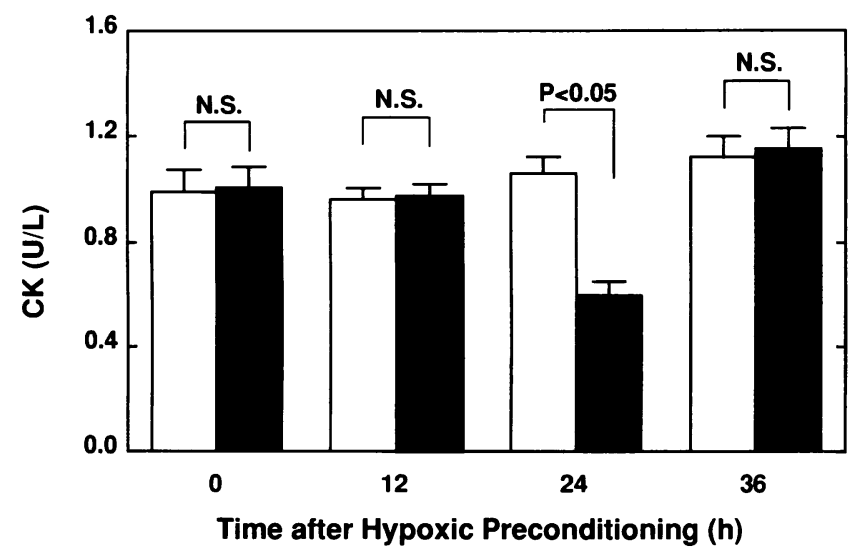

Figure 2. CK activity in culture medium after prolonged hypoxia. After hypoxic preconditioning for $1 \mathrm{~h}$, the cells were reoxygenated for 0,12 , 24 , or $36 \mathrm{~h}$. CK release after second reoxygenation for $1 \mathrm{~h}$ after sustained hypoxia for $3 \mathrm{~h}$ was measured. Control cells were exposed to normoxic conditions instead of hypoxic preconditioning for $1 \mathrm{~h}$. Open columns, control myocytes; hatched columns, preconditioned myocytes. Each statistic was derived using Student's unpaired $t$ test. Five batches of myocyte culture were examined for each experimental condition. Means \pm SEM.

ous contraction with increasing amplitude, and finally the cells hypercontracted. However, preconditioned cells showed less marked hypercontraction on reoxygenation, even after restarting spontaneous contraction. To evaluate myocyte injury quantitatively, we measured CK activity in culture media $1 \mathrm{~h}$ after the second reoxygenation (Fig. 2). When preconditioned myocytes were exposed to sustained hypoxia soon after, $12 \mathrm{~h}$ after, or 36 $\mathrm{h}$ after hypoxic preconditioning, the amount of $\mathrm{CK}$ released from preconditioned myocytes was the same as that released from myocytes without preconditioning. However, when the sustained hypoxia was applied $24 \mathrm{~h}$ after preconditioning, the amount of released CK from preconditioned myocytes was $57 \%$ of that from cells without preconditioning. Therefore, in the cultured myocyte model, simulation of ischemia by the exposure to hypoxia with low glucose exhibited the same protective effect as in vivo preconditioning at a later phase $(24 \mathrm{~h}$ after $)$. The composition of the culture medium was critical for simulating preconditioning by hypoxia. A low glucose concentration, the absence of insulin and transferrin during the hypoxic preconditioning, and the presence of high concentrations of glucose, insulin, and transferrin in the first reoxygenation medium were necessary for the induction of Mn-SOD by hypoxic preconditioning. The absence of glucose, insulin, and transferrin during the sustained hypoxia for $3 \mathrm{~h}$ was necessary to cause cell injury on the second reoxygenation.

$M n-S O D$ after hypoxic preconditioning. We investigated whether Mn-SOD was increased in cardiac myocytes after hypoxic preconditioning. Cardiac myocytes were exposed to hypoxic preconditioning for $1 \mathrm{~h}$, and then the Mn-SOD content and activity in myocytes were measured after reoxygenation for 36 h (Fig. 3). During the preconditioning, the Mn-SOD content in myocytes slightly decreased, reaching $83 \%$ of the prehypoxic value after $1 \mathrm{~h}$ of hypoxia. Upon reoxygenation, the Mn-SOD content increased gradually and reached $157 \%$ of the posthypoxic value at $24 \mathrm{~h}$ after reoxygenation. Thereafter, the Mn-SOD content decreased and returned to the prehypoxic value after 36 h of reoxygenation (Fig. 3, top). Simultaneously, the Mn-SOD

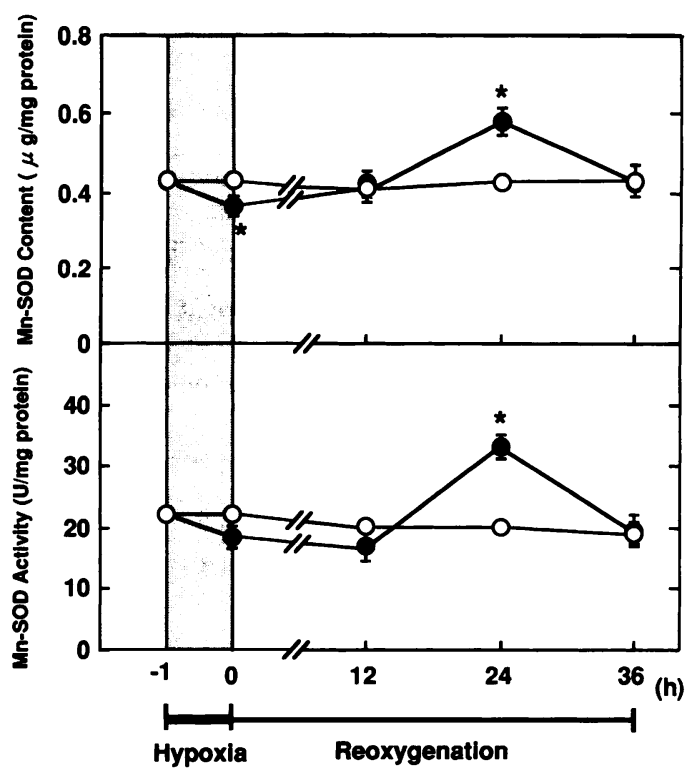

Figure 3. Mn-SOD content and activity in cultured cardiac myocytes. The SOD activity in cultured myocytes with (closed circles) or without (open circles) hypoxic preconditioning was determined by the NBT method. The Mn-SOD content in the supernatant was determined by ELISA, as described previously. Eight batches of myocyte culture were examined for each data point. Each statistic was derived using Student's unpaired $t$ test. Means \pm SEM. ${ }^{*} P<0.05$.

activity exhibited the same trend as the Mn-SOD content. It decreased to $83 \%$ during the hypoxia, reached $182 \%$ of the posthypoxic value after $24 \mathrm{~h}$ of reoxygenation, and then decreased to the control value after $36 \mathrm{~h}$ of reoxygenation (Fig. 3 , bottom). Therefore, the time course of Mn-SOD induction and reduction after hypoxic preconditioning was coincident with the time course of the acquisition of tolerance to hypoxia shown in Fig. 2. The duration of hypoxic preconditioning is important for the induction of Mn-SOD. When the duration was $<45$ $\mathrm{min}$, the Mn-SOD protein was not induced after $24 \mathrm{~h}$ of reoxygenation. When the duration was $>120 \mathrm{~min}$, the Mn-SOD content became $75 \%$ of the prehypoxic value and did not exceed the prehypoxic value even after $24 \mathrm{~h}$ of reoxygenation. However, the activity of the cytosolic isoform of SOD $(\mathrm{Cu}, \mathrm{Zn}$ SOD) did not decrease during hypoxic preconditioning for up to $3 \mathrm{~h}$ ( $102 \%$ of the prehypoxic value) or did not increase after reoxygenation after $1 \mathrm{~h}$ of hypoxic preconditioning and showed a gradual decrease during the reoxygenation period ( $90 \%$ of the control value after $24 \mathrm{~h}$ of reoxygenation). In the cells without hypoxic preconditioning (control group), both the MnSOD content and activity remained constant during this time period (Fig. 3, open circles). We also examined whether transcription of Mn-SOD mRNA was augmented by the exposure to hypoxic preconditioning. Total RNA was harvested from myocyte cultures from 10 to $60 \mathrm{~min}$ at 10 -min intervals, sizefractionated, and then hybridized to an Mn-SOD cDNA probe (Fig. $4 A$ ). Although the Mn-SOD protein level peaked at 24 $\mathrm{h}$, as shown in Fig. 3, the levels of Mn-SOD mRNA increased early after preconditioning (20-40 $\mathrm{min}$ ) and returned to the control level (Fig. 4, $A$ and $B$ ). The Mn-SOD mRNA levels remained constant thereafter, up to $23 \mathrm{~h}$ after reoxygenation (data not shown).

Induction of Mn-SOD and hypoxic tolerance. We examined 


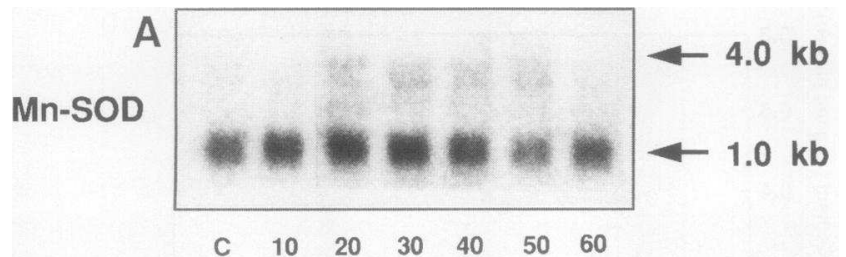

Time after Reoxygenation ( $\min )$

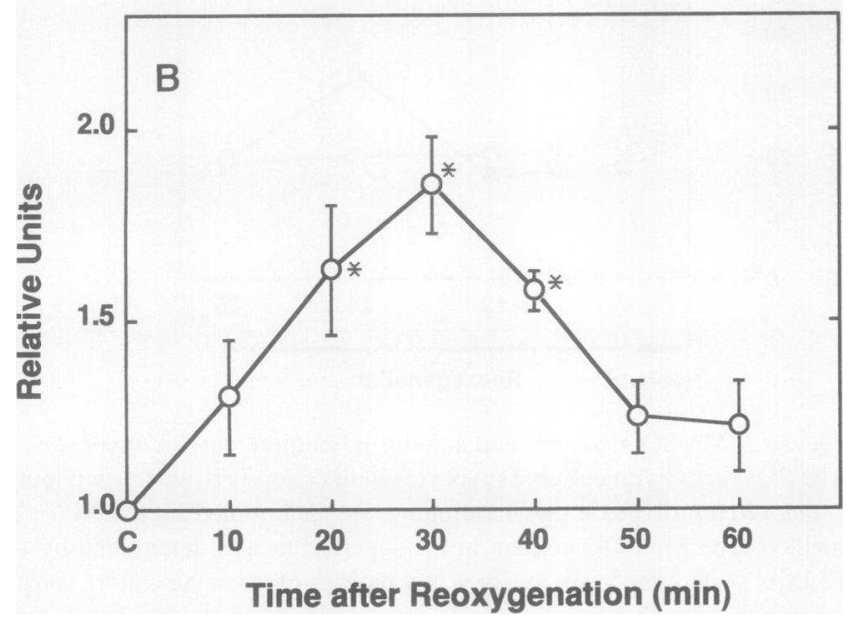

Figure 4. Effect of hypoxic preconditioning on Mn-SOD mRNA expression in cardiac myocytes. $(A)$ Total RNA was isolated from preconditioned cultured myocytes at 10-min intervals from 10 to 60 min after reoxygenation. RNA was analyzed by Northern blot hybridization after size fractionation using a rat Mn-SOD cDNA probe. Rat Mn-SOD mRNA gave two bands, corresponding to 4.0 and $1.0 \mathrm{~kb}$. $C$, myocytes before hypoxic preconditioning. $(B)$ Blots were also hybridized with a $\beta$-actin probe, and Mn-SOD signals were normalized to paired $\beta$-actin signals. Each value after hypoxic preconditioning (10-60 min) was compared with the value for the myocytes before hypoxic preconditioning $(C)$. More than three batches of experiment were done for each time point. Means \pm SEM. $* P<0.05$.

whether antisense ODN could inhibit the increases in Mn-SOD activity and content in cultured myocytes after hypoxic preconditioning (Fig. 5). Antisense ODN corresponding to the initiation site of Mn-SOD translation (22 mer: CACGCCGCCCGACACAACATTG, $1.5 \mu \mathrm{M}$ ) were added to myocyte cultures from $18 \mathrm{~h}$ before exposure to the hypoxic preconditioning to $24 \mathrm{~h}$ after the first reoxygenation, and the Mn-SOD content and activity were measured after $24 \mathrm{~h}$ of reoxygenation. The increases in both the Mn-SOD content and activity after hypoxic preconditioning were inhibited completely by the addition of antisense ODN. However, sense ODN (22 mer: CAATGTTGTGTCGGGCGGCGTG, $1.5 \mu \mathrm{M}$ ) did not attenuate the increase in either the Mn-SOD content or activity caused by preconditioning. A protein kinase $C$ inhibitor, staurosporine ( $100 \mathrm{nM})$, also markedly inhibited the expected increases in Mn-SOD content and activity in cultured myocytes with hypoxic preconditioning when added to the myocyte cultures after hypoxic preconditioning, which indicates that Mn-SOD was induced by a protein kinase $\mathrm{C}$-mediated pathway after hypoxic preconditioning.

We examined whether the increases in Mn-SOD activity and content in myocytes exposed to hypoxic preconditioning

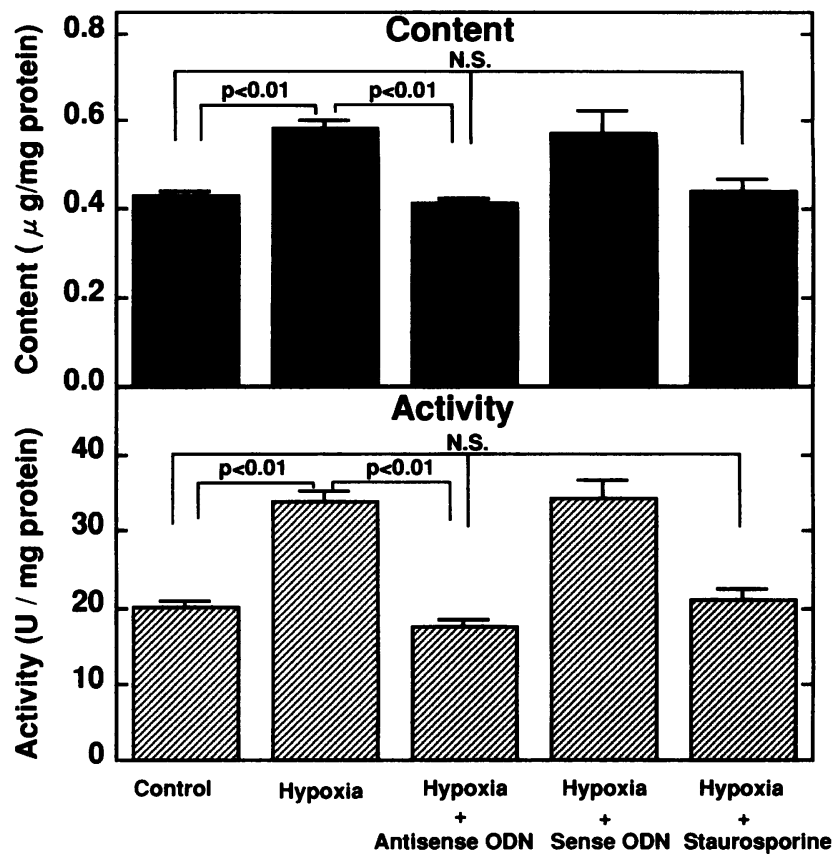

Figure 5. Effects of ODN and staurosporine on Mn-SOD content and activity in cultured myocytes. Myocytes were exposed to hypoxic preconditioning for $1 \mathrm{~h}$, followed by reoxygenation. The Mn-SOD content and activity in myocytes were measured at $24 \mathrm{~h}$ after reoxygenation. ODN were applied to cultures from $18 \mathrm{~h}$ before hypoxia to $24 \mathrm{~h}$ after reoxygenation. In experiments involving staurosporine, it (100 nM) was added to preconditioned cells for $24 \mathrm{~h}$ after reoxygenation. Five batches of myocyte culture were examined for each experimental condition. Each statistic was derived using Scheffe's test after ANOVA. Means \pm SEM.

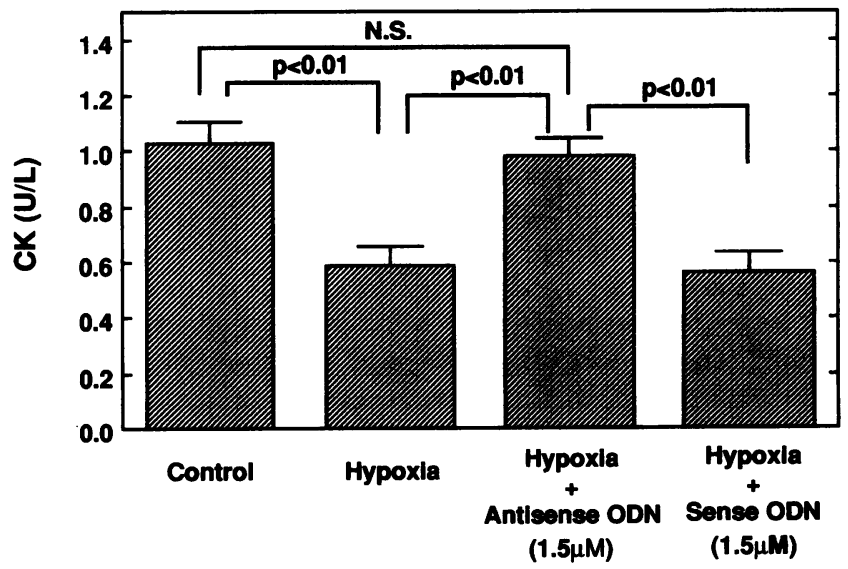

Figure 6. Effect of ODN on CK release from cultured cardiac myocytes after hypoxia-reoxygenation. Antisense and sense ODN were applied to preconditioned myocyte cultures at $1.5 \mu \mathrm{M}$ from $18 \mathrm{~h}$ before first hypoxia to $24 \mathrm{~h}$ after reoxygenation. In the control group, cultured cells were exposed to normoxic conditions instead of hypoxic preconditioning. CK activity in the culture medium was measured $1 \mathrm{~h}$ after reoxygenation after sustained hypoxia. Six batches of myocyte culture were examined for each experimental condition. Each statistic was derived using Scheffe's test after ANOVA. Means \pm SEM. 
were directly related to the protective effect of preconditioning using antisense ODN (Fig. 6). The expected decrease in CK release caused by hypoxic preconditioning was abolished in cultures pretreated with antisense ODN, in which Mn-SOD induction was specifically inhibited, as shown in Fig. 5. Sense ODN, which did not attenuate Mn-SOD induction, did not abolish the effect of hypoxic preconditioning on myocyte injury after sustained hypoxia. Possibly because of cytotoxicity, most of the myocytes pretreated with staurosporine hypercontracted, developed blebs, and became lifted up from the culture dishes on exposure to the second hypoxia, and thus $\mathrm{CK}$ release after sustained hypoxia from these cultures could not be examined.

\section{Discussion}

This is the first report showing that hypoxic preconditioning induces tolerance to hypoxia in cardiac myocytes at $24 \mathrm{~h}$ after preconditioning and that induction of Mn-SOD in myocytes is directly related to the mechanism underlying the tolerance to hypoxia. We found that $(a)$ exposure of myocytes to $1 \mathrm{~h}$ of hypoxia reduced $\mathrm{CK}$ release from the myocytes after exposure to sustained hypoxia when second hypoxia was applied to them $24 \mathrm{~h}$ after hypoxic preconditioning. However, the protective effect was not observed when the interval between the hypoxic preconditioning and the sustained hypoxia was 0,12 , or $36 \mathrm{~h}$. (b) The time course of the induction of tolerance to hypoxia was coincident with the time course of increase and decrease in $\mathrm{Mn}$-SOD in the myocytes; Mn-SOD was not induced in myocytes $12 \mathrm{~h}$ after preconditioning, but the Mn-SOD content and activity were about 1.3-2.0 times those in cells without preconditioning after $24 \mathrm{~h}$. This increase in Mn-SOD declined after $36 \mathrm{~h}$. (c) Mn-SOD induction was supposed to be transcriptionally regulated, because the Mn-SOD mRNA level was augmented soon after hypoxic preconditioning. $(d)$ The addition of antisense ODN corresponding to the initiation site of $\mathrm{Mn}$ SOD translation in myocyte cultures abolished both the induction of Mn-SOD in myocytes and the acquisition of tolerance to hypoxia after hypoxic preconditioning.

Cardiac myocyte model of preconditioning. Isolated cardiac myocytes were used as a model of ischemic heart diseases (19, 20). Recently, Ganote et al. (21) and Armstrong et al. (22) used isolated cardiac myocytes from adult rats and rabbits to examine the role of adenosine in early phase of preconditioning. They applied the "ischemic slurry" method to simulate ischemia instead of low oxygen tension in glucose-free medium which we used in this report. As the morphology and metabolism of neonatal myocytes are different from in situ adult myocytes, isolated adult cells might be suitable to mimic adult hearts. However, phenotypical change after isolation and the absence of contraction in these adult cells could raise the difference from in situ hearts. On the other hand, the phenotype of cultured neonatal myocytes is highly stable and their contractile profile during hypoxia-reoxygenation is compatible with in situ hearts during ischemia-reperfusion. Hypoxia with glycolysis inhibition is well established in mimicking ischemia in isolated cell models (19). Despite these limitations, both adult and neonatal myocyte systems simulated in situ preconditioning phenomena (time course, species difference, etc.) quite well.

Late phase effect of preconditioning. The preconditioning phenomenon was initially recognized soon after exposure to a brief ischemic episode (1). Repeated sublethal ischemia reduced the extent of myocardial cell death resulting from lethal ischemia applied immediately after sublethal ischemia. Although how long the protective effect of ischemic preconditioning remains has not been determined definitely, the consensus is that it is not maintained for more than $3 \mathrm{~h}(6,7)$. Recently, we examined the effect of repeated brief occlusion of the canine coronary artery on tolerance to ischemia from soon after to 24 $h$ after preconditioning (6). The size of myocardial infarction caused by prolonged ischemia was reduced significantly when the ischemia was introduced soon after preconditioning, compared with the group without ischemic preconditioning. However, the protective effect of ischemic preconditioning had disappeared $12 \mathrm{~h}$ after preconditioning. Surprisingly, when we exposed the canine heart to lethal prolonged ischemia $24 \mathrm{~h}$ after preconditioning, the extent of myocardial infarction was markedly reduced compared with the nonpreconditioned group. Recently, Marber et al. (8) also reported the reappearance of tolerance to ischemia at the "24-h window" after preconditioning.

Mechanism underlying the protective effect of preconditioning. The mechanism underlying the preconditioning phenomenon at an early phase is proposed to comprise a change in energy metabolism or activation of an adenosine receptor (2, $23,24)$. Protein induction was not involved in the mechanism underlying tolerance to ischemia at this phase because inhibitors of protein synthesis did not abolish the protective effect of preconditioning (9). However, many proteins, such as protooncogenes and stress proteins, were newly synthesized on stimulation with ischemia or hypoxia in heart tissue (25-29). Recently, we and others found that the synthesis of an endogenous radical scavenger, mitochondrial Mn-SOD, was increased in cardiac tissue after preconditioning $(10,25)$.

Tolerance caused by Mn-SOD induction. Mn-SOD acts as a rescue protein in several cells, and the induction of Mn-SOD by endotoxin (30) and cytokines (TNF- $\alpha$ [31-33] and IL-1 [34]) serves as a mechanism endowing tolerance to oxygen injury or antitumor agents. IL-1 pretreatment (35) and TNF- $\alpha$ (36) have also been reported to increase the tolerance to ischemia-reperfusion injury in hearts, which suggests that Mn-SOD induction could be the mechanism underlying the tolerance to ischemia in hearts. Our finding that inhibition of Mn-SOD induction by antisense ODN abolished the tolerance to hypoxia is the first direct evidence of Mn-SOD acting as a rescue protein in ischemic hearts at a late phase, the 24-h window, of preconditioning.

Catalase, another scavenger of an active oxygen species, hydrogen peroxide, was also induced in hearts on endotoxin treatment $(37)$ or heat shock $(38,39)$. Inhibition of catalase increased after heat shock, and endotoxin treatment abolished the protective effects of these stresses against ischemia, which indicates that catalase could be a rescue protein in ischemic hearts in these sets of experiments. Peroxisomal catalase was also found to be induced in a heart preconditioned by ischemia (25). However, the role of catalase in the acquisition of tolerance at preconditioning has not been examined yet.

Active oxygen species such as oxygen radicals, hydrogen peroxide, and lipid peroxides have been detected in ischemic and reperfused hearts $(40,41)$. They were supposed to be pathogenic factors for ischemic heart injury $(42,43)$ because exogenous radical scavengers $(44,45)$, inhibitors of lipid peroxidation $(46,47)$, and endogenous catalase induced by endotoxin (37) or heat shock (38) reduced ischemic and ischemic/reperfused heart injury. Therefore, Mn-SOD induced by precondi- 
tioning in our model may behave as an antioxidant in myocytes and scavenge superoxide anions generated on hypoxia/reoxygenation before causing myocyte injury on propagation of the radical chain reaction.

HSPs have also been reported to increase after stresses such as heat shock $(27,38)$ and hypoxic/ischemic preconditioning $(8,25-29)$, which was supposed to be related to the protection against ischemia. Recently, Hutter et al. (12) showed quantitative correlation between HSP72 induction and myocardial protection in a rat whole body hyperthermia model. However, there is little direct proof of a causal relationship between these two phenomena, and the mechanism in which heat shock proteins salvage myocytes from ischemia should be examined.

Mechanism underlying $M n-S O D$ induction. Mn-SOD activity showed a biphasic increase after preconditioning in an in vivo experiment (10). Induction soon after ischemic preconditioning is possibly due to conversion from pro Mn-SOD to MnSOD $(48)$ or a change in oligomer structure $(14,49)$. However, the Mn-SOD content increased together with the Mn-SOD activity at the 24-h window after preconditioning in this experiment and in our previous study (10), which suggests that de novo synthesis of the Mn-SOD protein occurs at a later phase of preconditioning. Various interventions are known to induce Mn-SOD in cells. Endotoxin (30), cytokines such as TNF- $\alpha$ (50), and IL-1 (34) increased Mn-SOD in endothelial cells and pulmonary tissue. In hearts, $x$-ray irradiation (51) increased $\mathrm{Mn}-\mathrm{SOD}$ in a biphasic manner. Induction of Mn-SOD was also observed in hypertrophic hearts produced by aortic binding (52).

Our results indicate that the mechanism underlying $\mathrm{Mn}$ SOD induction after hypoxic preconditioning is regulated at the transcriptional level. In prokaryotes, the Mn-SOD gene is under the control of cis elements responsible for anaerobic/aerobic states (53). However, the Mn-SOD gene of eukaryotes does not contain these cis elements. As an activator protein-1 site exists in the eukaryotic Mn-SOD gene (54) and a c-kinase inhibitor, staurosporine, inhibited Mn-SOD induction in our system, c-kinase activation and the following phosphorylation of activator protein-1 could be a possible pathway for Mn-SOD induction (55).

\section{Acknowledgments}

We thank Dr. Keiichiro Suzuki for providing the Mn-SOD polyclonal antibodies, and Ms. Tomoko Kawai for her excellent technical assistance.

This work was supported in part by a research grant from the Ministries of Education, Science and Culture (T. Kuzuya), and a grant from the Human Frontier Science Project (M. Tada).

\section{References}

1. Murry, C. E., R. B. Jennings, and K. A. Reimer. 1986. Preconditioning with ischemia: a delay of lethal cell injury in ischemic myocardium. Circulation. 74:1124-1136.

2. Murry, C. E., R. B. Jennings, and K. A. Reimer. 1991. New insights into potential mechanisms of ischemic preconditioning. Circulation. 84:442-445.

3. Deutsch, E., M. Berger, W. G. Kussmaul, J. W. J. Hirshfeld, H. C. Herrmann, and W. K. Laskey. 1990. Adaptation to ischemia during percutaneous transluminal coronary angioplasty. Clinical, hemodynamic, and metabolic features. Circulation. 82:2044-2051.

4. Kantengwa, S., Y. R. A. Donati, M. Clerget, I. Maridonneau-Parini, F. Sinclair, E. Mariethoz, M. Perin, A. D. M. Rees, D. O. Slosman, and B. S. Polla. 1991. Heat shock proteins: an autoprotective mechanism for inflammatory cells? Seminars in Immunology. 3:49-56.
5. Nishida, K., M. Mishima, A. Hirayama, N. Misaki, T. Masue, Y. Ueda, and K. Kodama. 1992. Limitation of infarct size by preinfarction angina through preconditioning but not collateral circulation. J. Am. Coll. Cardiol. 19: 56a. (Abstr.)

6. Kuzuya, T., S. Hoshida, N. Yamashita, H. Fuji, H. Oe, M. Hori, T. Kamada, and M. Tada. 1993. Delayed effects of sublethal ischemia on the acquisition of tolerance to ischemia. Circ. Res. 72:1293-1299.

7. Murry, C. E., V. J. Richard, R. B. Jennings, and K. A. Reimer. 1991. Myocardial protection is lost before contractile function recovers from ischemic preconditioning. Am. J. Physiol. 260:H796-H804.

8. Marber, M. S., D. S. Latchman, J. M. Walker, and D. M. Yellon. 1993. Cardiac stress protein elevation 24 hours after brief ischemia or heat stress is associated with resistance to myocardial infarction. Circulation. 88:1264-1272.

9. Thornton, J., S. Striplin, G. S. Liu, A. Swafford, A. W. Stanley, D. M. Van Winkle, and J. M. Downey. 1990. Inhibition of protein synthesis does not block myocardial protection afforded by preconditioning. Am. J. Physiol. 259:H1822H1825.

10. Hoshida, S., T. Kuzuya, H. Fuji, N. Yamashita, H. Oe, M. Hori, K. Suzuki, N. Taniguchi, and M. Tada. 1993. Sublethal ischemia alters myocardial antioxidant activity in canine heart. Am. J. Physiol. 264:H33-H39.

11. Currie, R. W., and R. M. Tanguay. 1991. Analysis of RNA for transcripts for catalase and SP71 in rat hearts after in vivo hyperthermia. Biochem. Cell Biol. 69:375-382.

12. Hutter, M. M., R. E. Sievers, V. Barbosa, and C. L. Wolfe. 1994. Heatshock protein induction in rat hearts. A direct correlation between the amount of heat-shock protein induced and the degree of myocardial protection. Circulation. 89:355-360.

13. Goshima, K. 1977. Ouabain-induced arrhythmias of single isolated myocardial cells and cell clusters cultured in vitro and their improvement by quinidine. J. Mol. Cell. Cardiol. 9:7-23.

14. Matsuda, Y., S. Higashiyama, Y. Kijima, K. Suzuki, K. Kawano, M. Akiyama, S. Kawata, S. Tarui, H. F. Deutsch, and N. Taniguchi. 1990. Human liver manganese superoxide dismutase. Purification and crystallization, subunit association and sulfhydryl reactivity. Eur. J. Biochem. 194:713-720.

15. Kawaguchi, T., K. Suzuki, Y. Matsuda, T. Nishiura, T. Uda, M. Ono, C. Sekiya, M. Ishikawa, S. lino, Y. Endo, and N. Taniguchi. 1990. Serum-manganese-superoxide dismutase: normal values and increased levels in patients with acute myocardial infarction and several malignant diseases determined by an enzyme-linked immunosorbent assay using a monoclonal antibody. J. Immunol. Methods. 127:249-254.

16. Chomczynski, P., and N. Sacchi. 1987. Single-step method of RNA isolation by acid guanidium thiocyanate-phenol-chloroform extraction. Anal. Biochem. 162:156-159.

17. Ho, Y.-S., and J. D. Crapo. 1987. Nucleotide sequences of cDNAs coding for rat manganese-containing superoxide dismutase. Nucleic Acids Res. 15:10070.

18. Recommendations of the German Society for Clinical Chemistry. 1977. Standard method for the determination of creatine kinase activity. J. Clin. Chem. Clin. Biochem. 15:255-260.

19. Allen, D. G., and C. H. Orchard. 1987. Myocardial contractile function during ischemia and hypoxia. Circ. Res. 60:153-168.

20. Nishida, M., S. Borzak, B. Kraemer, J. P. Navas, R. A. Kelly, T. W. Smith, and J. D. Marsh. 1993. Role of cation gradients in hypercontracture of myocytes during simulated ischemia and reperfusion. Am. J. Physiol. 264:H1896H1906.

21. Ganote, C. E., S. Armstrong, and J. M. Downey. 1993. Adenosine and A1 selective agonists offer minimal protection against ischaemic injury to isolated rat cardiomyocytes. Cardiovasc. Res. 27:1670-1676.

22. Armstrong, S., J. M. Downey, and C. E. Ganote. 1994. Preconditioning of isolated rabbit cardiomyocytes: induction by metabolic stress and blockade by the adenosine antagonist SPT and calphostin $\mathrm{C}$, a protein kinase $\mathrm{C}$ inhibitor. Cardiovasc. Res. 28:72-77.

23. Murry, C. E., V. J. Richard, K. A. Reimer, and R. B. Jennings. 1990. Ischemic preconditioning slows energy metabolism and delays ultrastructural damage during a sustained ischemic episode. Circ. Res. 66:913-931.

24. Liu, G. S., J. Thornton, D. M. Van Winkle, A. W. Stanley, R. A. Olsson, and J. M. Downey. 1991. Protection against infarction afforded by preconditioning is mediated by $\mathrm{Al}$ adenosine receptors in rabbit heart. Circulation. 84:350-356.

25. Das, D. K., R. M. Engelman, and Y. Kimura. 1993. Molecular adaptation of cellular defences following preconditioning of the heart by repeated ischaemia. Cardiovasc. Res. 27:578-584.

26. Iwaki, K., S.-H. Chi, W. H. Dillmann, and R. Mestril. 1993. Induction of HSP70 in cultured rat neonatal cardiomyocytes by hypoxia and metabolic stress. Circulation. 87:2023-2032.

27. Currie, R. W. 1987. Effects of ischemia and perfusion temperature on the synthesis of stress-induced (heat shock) proteins in isolated and perfused rat hearts. J. Mol. Cell. Cardiol. 19:795-808.

28. Knowlton, A. A., P. Brecher, and C. S. Apstein. 1991. Rapid expression of heat shock protein in the rabbit after brief cardiac ischemia. J. Clin. Invest. 87:139-147.

29. Dillmann, W. H., H. B. Mehta, A. Barrieux, B. D. Guth, W. E. Neeley, 
and J. Ross, Jr. 1986. Ischemia of the dog heart induces the appearance of a cardiac mRNA coding for a protein with migration characteristics similar to heatshock/stress protein 71. Circ. Res. 59:110-114.

30. Shiki, Y., B. O. Meyrick, K. L. Brigham, and I. M. Burr. 1987. Endotoxin increases superoxide dismutase in cultured bovine pulmonary endothelial cells. Am. J. Physiol. 252:C436-C440.

31. Warner, B. B., M. S. Burhans, J. C. Clark, and J. R. Wispe. 1991. Tumor necrosis factor- $\alpha$ increases Mn-SOD expression: protection against oxidant injury Am. J. Physiol. 260:L296-L301.

32. Wong, G. H. W., J. H. Elwell, L. W. Oberley, and D. V. Goeddel. 1989 Manganous superoxide dismutase is essential for cellular resistance to cytotoxicity of tumor necrosis factor. Cell. 58:923-931.

33. Wong, G. H. W., and D. V. Goeddel. 1988. Induction of manganous superoxide dismutase by tumor necrosis factor: possible protective mechanism. Science (Wash. DC). 242:941-944.

34. Masuda, A., D. L. Longo, Y. Kobayashi, E. Appella, J. J. Oppenheim, and $\mathrm{K}$. Matsushima. 1988. Induction of mitochondrial manganese superoxide dismutase by interleukin 1. FASEB (Fed. Am. Soc. Exp. Biol.) J. 2:3087-3091.

35. Brown, J. M., C. W. White, L. S. Terada, M. A. Grosso, P. F. Shanley, D. W. Mulvin, A. Banerjee, G. J. Whitman, A. H. Harken, and J. E. Repine. 1990. Interleukin 1 pretreatment decreases ischemia/reperfusion injury. Proc. Natl. Acad. Sci. USA. 87:5026-5030.

36. Eddy, L. J., D. V. Goeddel, and G. H. W. Wong. 1992. Tumor necrosis factor- $\alpha$ pretreatment is protective in a rat model of myocardial ischemia-reperfusion injury. Biochem. Biophys. Res. Commun. 184:1056-1059.

37. Brown, J. M., M. A. Grosso, L. S. Terada, G. J. R. Whitman, A. Banerjee, C. W. White, A. H. Harken, and J. E. Repine. 1989. Endotoxin pretreatmen increases endogenous myocardial catalase activity and decreases ischemia-reperfusion injury of isolated rat hearts. Proc. Natl. Acad. Sci. USA. 86:2516-2520.

38. Karmazyn, M., K. Mailer, and R. W. Currie. 1990. Acquisition and decay of heat-shock-enhanced postischemic ventricular recovery. Am. J. Physiol 259:H424-H431.

39. Barrett, L. V., J. R. Murphy, T. B. Strom, and R. L. Kirkman. 1989. Treatment with a diphtheria toxin-related interleukin 2 fusion protein prolongs cardiac allograft survival in mice. Transplant. Proc. 21:1130-1131.

40. Zweier, J. L., J. T. Flaherty, and M. L. Weisfeldt. 1987. Direct measurement of free radical generation following reperfusion of ischemic myocardium Proc. Natl. Acad. Sci. USA. 84:1404-1407.

41. Kuzuya, T., S. Hoshida, Y. Kim, M. Nishida, H. Fuji, A. Kitabatake, M. Tada, and T. Kamada. 1990. Detection of oxygen-derived free radical generation in the canine postischemic heart during late phase of reperfusion. Circ. Res. $66: 1160-1165$
42. Kuzuya, T., S. Hoshida, Y. Kim, H. Oe, M. Hori, T. Kamada, and M. Tada. 1993. Free radical generation coupled with arachidonate lipoxygenase reaction related to reoxygenation induced myocardial cell injury. Cardiovasc. Res. 27:957-961.

43. Shlafer, M., P. F. Kane, V. Y. Wiggins, and M. M. Kirsh. 1982. Possible role for cytotoxic oxygen metabolites in the pathogenesis of cardiac ischemic injury. Circulation. 66:185-192.

44. Jolly, S. R., W. J. Kane, M. B. Bailie, G. D. Abrams, and B. R. Lucchesi. 1984. Canine myocardial reperfusion injury. Its reduction by the combined administration of superoxide dismutase and catalase. Circ. Res. 54:277-285.

45. Kuzuya, T., S. Hoshida, M. Nishida, Y. Kim, H. Fuji, A. Kitabatake, T. Kamada, and M. Tada. 1989. Myocardial salvage by a novel free radical scavenger, 2-octadecylascorbic acid. Cardiovasc. Res. 23:323-330.

46. Bedner, M., B. Smith, A. Pinto, and K. M. Mullane. 1985. Nafazatrominduced salvage of ischemic myocardium in anesthetized dogs is mediated through inhibition of neutrophil function. Circ. Res. 57:131-141.

47. Hoshida, S., T. Kuzuya, M. Nishida, Y. Kim, A. Kitabatake, T. Kamada, and M. Tada. 1989. Attenuation of neutrophil function by inhibitors of arachidonate metabolism reduces the extent of canine myocardial infarction. Am. J. Cardiol. 63:24E-28E

48. Wispe, J. R., J. C. Clark, M. S. Bruhans, K. E. Kropp, T. R. Korfhagen, and J. A. Whitsett. 1989. Synthesis and processing of the precursor for human mangano-superoxide dismutase. Biochim. Biophys. Acta. 994:30-36.

49. Stallings, W. C., K. A. Pattridge, R. K. Strong, and M. L. Ludwig. 1985. The structure of manganese superoxide dismutase from Thermus thermophilus HB8 at 2.4-A resolution. J. Biol. Chem. 260:16424-16432.

50. Tsan, M.-F., J. E. White, C. Treanor, and J. B. Shaffer. 1990. Molecular basis for tumor necrosis factor-induced increase in pulmonary superoxide dismutase activities. Am. J. Physiol. 259:L506-L512.

51. Oberley, L. W., D. K. St. Clair, A. P. Autor, and T. D. Oberley. 1987. Increase in manganese superoxide dismutase activity in the mouse heart after $\mathrm{x}$ irradiation. Arch. Biochem. Biophys. 254:69-80.

52. Gupta, M., and P. K. Singal. 1989. Higher antioxidative capacity during a chronic stable heart hypertrophy. Circ. Res. 64:398-406.

53. Hassan, H. M., and H.-C. H. Sun. 1992. Regulatory roles of Fnr, Fur, and Arc in expression of manganese-containing superoxide dismutase in Escherichia coli. Proc. Natl. Acad. Sci. USA. 89:3217-3221.

54. Ho, Y.-S., A. J. Howard, and J. D. Crapo. 1991. Molecular structure of a functional rat gene for manganese-containing superoxide dismutase. Am. J. Respir. Cell Mol. Biol. 4:278-286.

55. Fujii, J., and N. Taniguchi. 1991. Phorbol ester induces manganese-superoxide dismutase in tumor necrosis factor-resistant cells. J. Biol. Chem. 266:23142-23146. 